09

\title{
Метод регистрации излучения \\ ИК-диапазона посредством ультразвуковой термометрии
}

\author{
() Д.В. Петров ${ }^{1,2}$, Д.Е. Генин ${ }^{3}$, В.А. Корольков ${ }^{1}$ \\ ${ }^{1}$ Институт мониторинга климатических и экологических систем СО РАН, \\ Томск \\ ${ }^{2}$ Национальный исследовательский Томский государственный \\ университет \\ ${ }^{3}$ Институт сильноточной электроники СО РАН, Томск \\ E-mail: dpetrov@imces.ru
}

Поступило в Редакцию 17 мая 2016 г.

Рассмотрен способ регистрации излучения ИК-диапазона, основанный на использовании метода ультразвуковой термометрии. Представлены первые результаты экспериментальной апробации данного метода на примере регистрации излучения $\mathrm{CO}_{2}$-лазера, а также приведены способы увеличения его пороговой чувствительности.

DOI: 10.21883/PJTF.2017.09.44572.16335

На сегодняшний день наблюдается активное освоение длинноволнового оптического диапазона (дальний ИК, ТНz), имеющего большие перспективы в областях биологии, медицины, безопасности и многих других. В связи с этим возникает потребность в приемниках данного излучения, обладающих улучшенными эксплуатационными характеристиками [1,2]. Из класса фотонных приемников считаются перспективными узкозонные полупроводниковые детекторы на основе $\mathrm{HgCdTe}, \mathrm{PbSnTe}, \mathrm{Ge}: \mathrm{Cu}, \mathrm{Ge}: \mathrm{Hg}$, имеющие чувствительность в среднем и дальнем ИК-диапазоне $(<30 \mu \mathrm{m})$ [3]. Однако из-за технологических трудностей при их производстве они пока относительно дороги, а при работе требуют охлаждения до криогенных температур, что существенным образом затрудняет их применение. Тепловые фотоприемники, известные своей широкополосностью и способностью работать при комнатной температуре, также имеют свои недостатки, среди которых низкое быстродействие и слабая чувствительность по сравнению с 
фотонными. Тем не менее одним из самых чувствительных фотоприемников, представленных сегодня на рынке и работающих при комнатной температуре как в дальнем ИК-, так и в THz-диапазонах, является детектор Голея [4-6]. В данном типе детектора измерение энергии основывается на том, что падающее излучение вызывает внутри герметичной камеры нагрев газа, и гибкой мембраной регистрируется увеличение его объема. Недостатками таких фотоприемников являются их относительно высокая стоимость, габариты, а также подверженность влиянию вибрационных помех.

В данной статье рассматривается способ регистрации излучения, схожий с используемым в детекторе Голея, но основывающийся на измерении температуры газа.

Основная идея предлагаемого подхода заключается в том, что при поглощении энергии излучения изменение температуры газа, находящегося в герметичной камере, может быть определено посредством ультразвуковой термометрии [7]. Известно, что скорость звука $(c)$ в газе однозначно связана с его температурой $(T)$ соотношением [8]

$$
c=\sqrt{\frac{\chi R T}{\mu}},
$$

где $\chi=C_{p} / C_{v}$ - отношение теплоемкостей данного газа при постоянном давлении и постоянном объеме, $R-$ универсальная газовая постоянная, $\mu-$ молекулярный вес газа.

В соответствии с этим изменение температуры газа может быть определено из соотношения

$$
\Delta T=\frac{\mu}{\chi R}\left(c_{2}^{2}-c_{1}^{2}\right),
$$

где $c_{1}$ и $c_{2}-$ скорости распространения звука в газе при температу$\operatorname{pax} T_{1}$ и $T_{2}$ соответственно.

Таким образом, в случае поглощения внутри герметичной камеры, наполненной газом, падающего оптического излучения его энергия $(E)$ может быть определена посредством измерения скоростей звука в данном газе до воздействия излучения $\left(c_{1}\right)$ и после $\left(c_{2}\right)$ :

$$
E=k\left(c_{2}^{2}-c_{1}^{2}\right),
$$

где $k-$ коэффициент пропорциональности, который может быть рассчитан аналитически либо определен эмпирически путем калибровочных измерений.

Письма в ЖТФ, 2017, том 43, вып. 9 


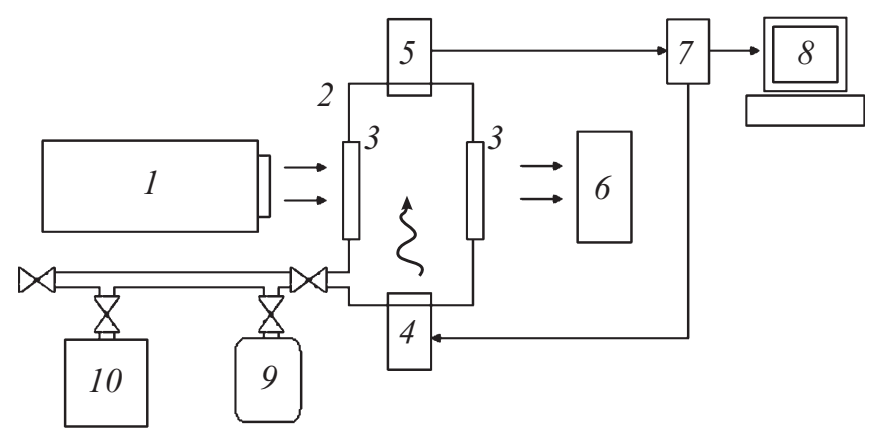

Рис. 1. Блок-схема экспериментальной установки: $1-\mathrm{CO}_{2}$-лазер, $2-$ измерительная камера, наполненная газом, 3 - окна камеры $\left(\mathrm{CaF}_{2}\right), 4-$ излучатель УЗ-колебаний, 5 - приемник УЗ-колебаний, 6 - фотоприемник Ophir, 7 блок питания и электроники, $8-$ ПК, $9-$ баллон с $\mathrm{SF}_{6}, 10-$ форвакуумный насос.

Методы измерения скорости звука на сегодняшний день достаточно хорошо развиты и относительно просты в реализации. Ввиду этого температура газовой среды может быть измерена с относительно малой инерционностью $(<10 \mathrm{~ms})$ при чувствительности $0.01 \mathrm{~K}$ [9].

Необходимо отметить, что поглощение оптического излучения может быть осуществлено как черным телом (в качестве поглощающего элемента) с последующей отдачей тепла газу, так и непосредственно самим газом или газовой смесью. В нашем случае экспериментальная апробация описанного выше метода была проведена на примере регистрации излучения с длиной волны $\lambda=10.6 \mu \mathrm{m}$ от импульсного $\mathrm{CO}_{2}$-лазера путем его поглощения специально подобранной газовой средой, находящейся внутри герметичной камеры (рис. 1).

Для проведения экспериментов была изготовлена камера внутренним объемом $11 \mathrm{~cm}^{3}$ с ортогональной схемой совмещения путей распространения акустического и оптического излучений. Внутри нее на расстоянии $64 \mathrm{~mm}$ друг от друга были установлены излучатель и приемник ультразвуковых (УЗ) колебаний частотой $\sim 120 \mathrm{kHz}$. Скорость распространения звука между ними определялась путем измерения времени пролета УЗ-импульсов с частотой следования $10 \mathrm{~Hz}$. В соответствии с тактовой частотой используемого АЦП $(32 \mathrm{MHz})$ и расстоянием между УЗ-излучателем и приемником минимальная 
регистрируемая величина изменения скорости звука внутри камеры составила $\sim 0.05 \mathrm{~m} / \mathrm{s}$, что соответствует изменению температуры $0.09 \mathrm{~K}$ (в атмосферном воздухе при нормальных условиях).

Также необходимо отметить, что расстояние между входным и выходным окнами камеры составляло $25 \mathrm{~mm}$, а диаметр УЗ-излучателя и приемника - $12 \mathrm{~mm}$. Используемый лазер [10] с установленной диафрагмой на выходе диаметром $12 \mathrm{~mm}$ обеспечивал генерацию импульсов с энергией $320 \pm 10 \mathrm{~mJ}$ длительностью $50 \mathrm{~ns}$ (на полувысоте). Контроль энергии излучения производился фотоприемником Ophir c сенсорными головками PE-50BB и FL250A-EX-SH.

В качестве газа, поглощающего оптическое излучение в области $10.6 \mu \mathrm{m}$, был выбран элегаз $\left(\mathrm{SF}_{6}\right)$, который обладает интенсивными полосами поглощения в данном диапазоне [11]. Проведенный теоретический расчет показал, что ввиду высокого коэффициента поглощения $\left(\sim 60 \mathrm{~cm}^{-1}\right)$ при его содержании в камере уже на уровне $0.05 \mathrm{~atm}$ происходит поглощение более $99.9 \%$ падающего излучения. Однако такая среда характеризуется крайне высоким коэффициентом затухания ультразвука. Ввиду этого был использован буферный газ, в качестве которого был выбран атмосферный воздух. Суммарное давление внутри камеры составляло $1 \mathrm{~atm}$.

В ходе проведения экспериментов по апробации метода камера наполнялась газовой средой с различным парциальным давлением $\mathrm{SF}_{6}$, после чего внутрь нее направлялось лазерное излучение и регистрировалось изменение скорости звука и соответственно температуры. Полученные экспериментальные результаты представлены на рис. 2. В случае нахождения внутри камеры $\mathrm{SF}_{6}$, после воздействия лазерного излучения регистрировалось резкое изменение температуры с последующим ее уменьшением (в течение $\sim 3 \mathrm{~s}$ ). Время отклика в соответствии с частотой следования УЗ-импульсов составляло $100 \mathrm{~ms}$. В случае наполнения камеры чистым воздухом изменения его температуры после воздействия лазерного излучения не происходило, даже несмотря на нагревание окон камеры, ввиду относительно низких коэффициентов пропускания $(\sim 45 \%)$. Помимо этого, наблюдалась различная максимальная регистрируемая величина изменения температуры газовой среды при различном парциальном давлении $\mathrm{SF}_{6}$. Данные результаты объясняются различным распределением тепла внутри камеры, выделяющегося в результате поглощения лазерного излучения. На рис. 3 представлен результат моделирования зависимостей ослабления лазерного импульса

Письма в ЖТФ, 2017, том 43, вып. 9 


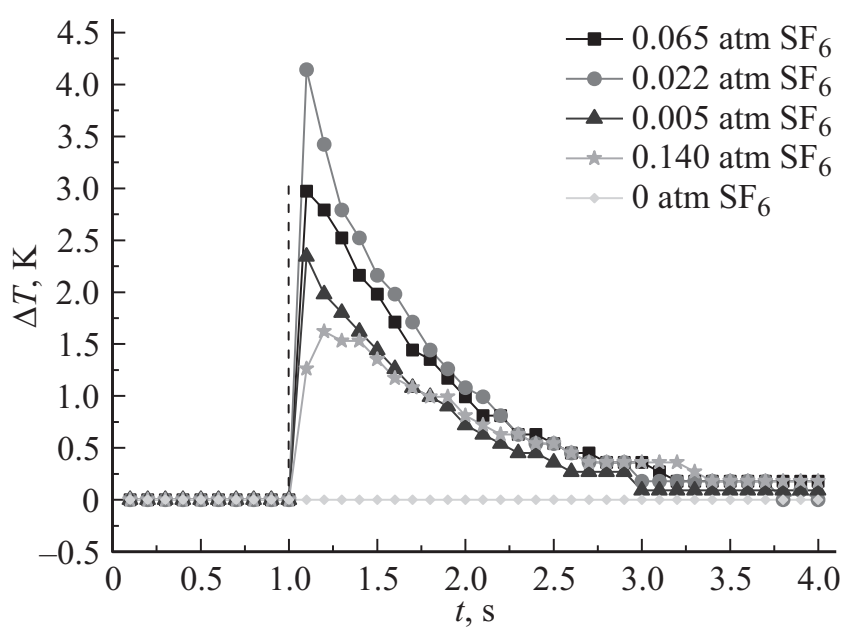

Рис. 2. Динамика изменения температуры газа внутри камеры при различных парциальных давлениях $\mathrm{SF}_{6}$. Пунктирная линия - момент воздействия лазерного импульса.

при его распространении внутри камеры, наполненной газовой смесью с различными парциальными давлениями $\mathrm{SF}_{6}$. Сопоставляя данные, приведенные на рис. 2 и 3, можно видеть, что зарегистрированные величины изменения температуры газа коррелируют с величинами поглощенной энергии непосредственно внутри области распространения УЗ-импульсов.

Согласно полученным данным, наибольшая величина нагрева была зафиксирована при парциальном давлении $\mathrm{SF}_{6}$, равном $0.022 \mathrm{~atm}$, и составила $4.3 \mathrm{~K}$. Исходя из величины энергии лазерного излучения и чувствительности используемой системы регистрации скорости распространения УЗ, следует, что пороговая чувствительность метода с данной измерительной камерой составила $\sim 7 \mathrm{~mJ}$. Необходимо отметить, что в данном случае, в соответствии с теоретическими расчетами, температура газа (до релаксации на стенках) в области взаимодействия с лазерным лучом должна была увеличиться на величину, близкую к $50 \mathrm{~K}$, а после усреднения по всему объему камеры на $\sim 10.5 \mathrm{~K}$. Таким образом, при оптимизации внутренних размеров измерительной камеры, а также при увеличении частоты следования УЗ-импульсов,

Письма в ЖТФ, 2017, том 43, вып. 9 


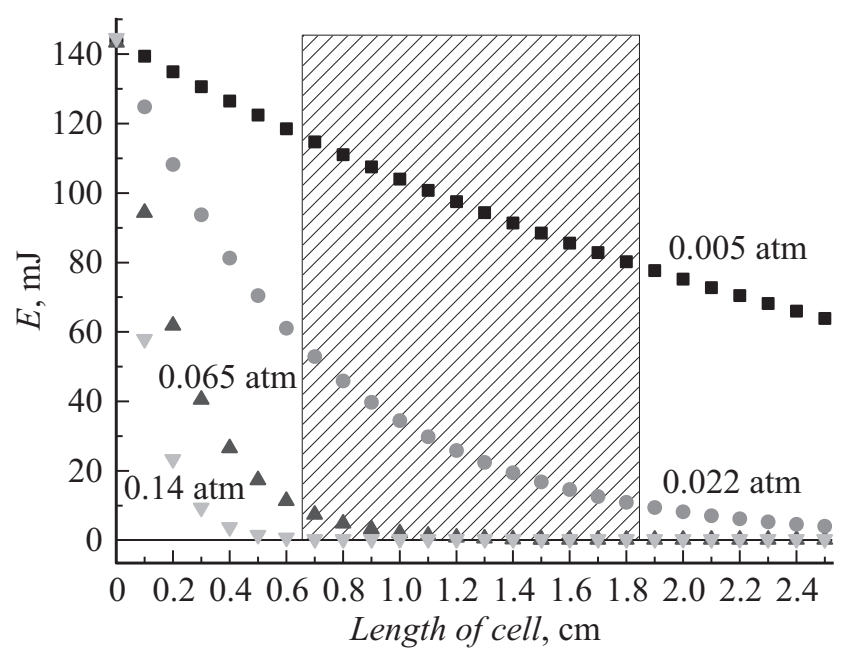

Рис. 3. Динамика ослабления энергии лазерного импульса внутри камеры при различных парциальных давлениях $\mathrm{SF}_{6}$. Штриховкой выделена область распространения ультразвука.

которая может быть увеличена минимум на несколько порядков, инерционность будет меныше, а максимальная регистрируемая величина нагрева будет больше, в результате чего пороговая чувствительность метода будет существенно улучшена. Также стоит отметить, что данный метод может быть использован без дополнительных компонентов для измерения энергии импульсов с большой пиковой мощностью ввиду отсутствия элементов, которые могут быть ими повреждены.

Таким образом, полученные результаты показывают, что на основе предложенного метода может быть создан селективный фотоприемник с большим динамическим диапазоном для регистрации излучения в области $10.6 \mu \mathrm{m}$. Помимо этого, путем подбора подходящей газовой среды либо путем использования черного тела для поглощения излучения и последующей отдачи тепла газу возможно осуществление при помощи данного метода регистрации излучения еще более длинноволнового диапазона (дальний ИК, THz).

Работа выполнена при поддержке РФФИ и Фонда „Национальное интеллектуальное развитие“ (грант № 16-32-80039).

Письма в ЖТФ, 2017, том 43, вып. 9 


\section{Список литературы}

[1] Sizov F., Rogalsky A. // Prog. Quantum Electron. 2010. V. 34. P. 278-347.

[2] Войцеховский А.В., Несмелов С.Н., Кульчицкий Н.А. и др. // Нано- и микросистемная техника. 2012. № 3. С. 25-34.

[3] Rogalsky A. // Infrared Phys. Technol. 2002. V. 43. P. 187-210.

[4] Ledwosinska E., Szkopek T., Guermoune A., Siaj M. // Proc. SPIE. 2012. V. 8261. P. 82610A.

[5] Иглакова А.Н., Ошлаков В.К., Селезнев Л.В., Тихомиров Б.А. // Оптика атмосферы и океана. 2015. Т. 28. № 4. С. 354-358.

[6] Гельфанд А.В., Паулиш А.Г., Федоринин В.Н. // Прикладная физика. 2009. № 2. C. 109-114.

[7] Корольков В.А. // Патент РФ № 2208224. Бюллетень изобретений. 2001. № 2.

[8] Красильников В.А., Крылов В.В. Введение в физическую акустику. М.: Наука, 1984. $400 \mathrm{c}$.

[9] Азбукин А.А., Богушевич А.Я., Кобзев А.А. и др. // Датчики и системы. 2012. № 3. C. 47-52.

[10] Орловский В.М., Панченко А.Н., Тарасенко В.Ф. // Квантовая электроника. 2010. T. 40. № 3. С. 192-194.

[11] Михайленко С.Н., Бабиков Ю.Л., Головко В.Ф. // Оптика атмосферы и океана. 2005. Т. 18. № 9. С. 765-776. 